\title{
LA INTERVENCIÓN DE MAGNUS MAXIMUS (383-388) EN EL CONFLICTO PRISCILIANISTA*
}

\author{
POR \\ MARÍA VICTORIA ESCRIBANO PAÑO ${ }^{1}$ \\ Universidad de Zaragoza
}

\begin{abstract}
RESUMEN
La intervención del usurpador Magnus Maximus en el conflicto priscilianista se ha explicado, de manera preferente, como un ejemplo de la injerencia del poder imperial en asuntos eclesiásticos y en clave legitimista. La finalidad de este artículo es explorar otras perspectivas. Se analizan las iniciativas del Augusto de Tréveris en relación con los obispos implicados en la disputa y su interpretación personal de la función religiosa imperial en los conflictos religiosos después de los juicios de Tréveris. De la comparación emerge un emperador respetuoso con las leyes y la tradición eclesiástica.
\end{abstract}

PALABRAS CLAVE: usurpador; herejía; obispo; concilio; iudicium publicum.

\section{THE INTERVENTION OF MAGNUS MAXIMUS (383-388) IN THE PRISCILIANIST CONFLICT}

\begin{abstract}
Intervention of the usurper Magnus Maximus in the Priscillianist conflict has been primarily explained as a legitimistic interference of imperial power in ecclesiastical affairs. The aim of this paper is to explore alternative points of view by analysing initiatives of the Augustus of Trier regarding bishops involved in the controversy, as well as his personal interpretation of the imperial religious function in religious conflicts after Trier trials. From this comparation emerges an emperor respectful of laws and ecclesiastical tradition.
\end{abstract}

KEY WORDS: usurper; heresy; bishop; council; iudicium publicum.

Cómo CITAR ESTE ARTículo / CITATION: Escribano Paño, María Victoria. 2021. «La intervención de Magnus Maximus (383-388) en el conflicto priscilianista». Hispania Sacra LXXIII, 147: 67-76. https://doi.org/10.3989/hs.2021.006

$\begin{array}{lr}\text { Recibido/Received } & 21-02-2019 \\ \text { Aceptado/Accepted } & 12-09-2019\end{array}$

La intervención de Máximo en el conflicto priscilianista ha merecido una atención subordinada al estudio de sus estrategias de legitimación tras su instalación en Tréveris. ${ }^{2}$ La persecución de la herejía y la instrumentalización de la religión formarían parte de la construcción de su legitimidad. ${ }^{3}$ Sin soslayar esta perspectiva, en este artículo se exploran,

\footnotetext{
Este trabajo forma parte del proyecto de investigación HAR2016-77003-P, financiado por la Agencia Estatal de Investigación del Ministerio de Ciencia, Innovación y Universidades.$$
1 \text { vescriba@unizar.es / }
$$$$
\text { ORCID iD: https://orcid.org/0000-0001-7903-0883 }
$$

2 Vollmann 1974; Chadwick 1976, 151-199; Escribano Paño 1988, 314-384; Burrus 1995, 94-101.

3 Birley 1983.
}

en una primera parte, las iniciativas del usurpador en relación con el conflicto y, en la segunda, las explicaciones que ofreció a Siricio de Roma sobre las mismas. Se trata de averiguar la coherencia entre las mismas.

\section{Controversia RELIGIOSA y CONTEXto político}

La primera información que recibió Máximo del conflicto priscilianista fue poco después de instalarse en Tréveris en agosto de 383 y a través del obispo de Ossonoba (Estoi), Itacio. ${ }^{4}$ Según Sulpicio Severo, este presentó ante el empera-

\footnotetext{
4 Vilella 1997.
} 
dor súplicas llenas de odio y de crímenes contra Prisciliano y sus partidarios. ${ }^{5}$ Itacio se encontraba oculto en Tréveris bajo la protección del obispo de la ciudad, Britanio. ${ }^{6}$ Había sido acusado de perturbator ecclesiarum y el magister officiorum de Graciano, Macedonio, había ordenado que fuera trasladado a Hispania para ser juzgado ante el tribunal del vicario de las Hispanias. Tras conocer la proclamación de Máximo en Britania, ${ }^{7}$ a pesar de la debilidad de su situación -licet rebus dubiis - Itacio esperó la llegada del nuevo emperador a la ciudad interim sibi nihil agitandum. ${ }^{8}$ Este es un dato de importancia. Sulpicio deja entender que Itacio, en colaboración con Britanio, concibió con premeditación un cambio de su suerte ligado al inminente cambio político. Máximo era hispano y cristiano niceno, ${ }^{9}$ había servido a las órdenes de Teodosio padre en Britania y África, ${ }^{10}$ donde pudo conocer personalmente a Teodosio I, y había eliminado a Graciano, cuyo staff en Milán, con el poderoso magister officiorum Macedonio al frente, después de la inicial hostilidad hacia Prisciliano y sus seguidores, había rectificado y se había mostrado favorable a su causa. ${ }^{11}$

La información recibida de Itacio en forma de preces era la defendida por la parte episcopal antipriscilianista con cuatro puntos relevantes: los priscilianistas practicaban ritos asociados con la magia, ${ }^{12}$ habían sido condenados en el concilio de Caesaraugusta, ${ }^{13}$ eran falsos obispos y maniqueos

\footnotetext{
5 Sulp. Sev. Chron. 2, 49, 6: igitur ubi Maximus oppidum Treuerorum uictor ingressus est, ingerit preces plenas in Priscillianum ac socios eius inuidiae atque criminum.

6 Britto (c. 374-386), había sucedido a Bonosus (c. 358-373) y precedió a Felix (c. 386-399). Vid. Duchesne 1915. Sobre su implicación en la cuestión priscilianista, vid. Binsfeld 2003.
}

Sobre los motivos de la usurpación Amm. 21,10,18-19, Zos. 4,35,2-6 y Aur. Vict. Epit. 47, 6. Vid. estado de la cuestión al respecto en Omissi 2018, 263-265.

8 Sulp. Sev. Chron. 2, 49, 1-5: uerum Ithacio ad resistendum non animus, sed facultas defuit, quia haeretici corrupto Voluentio proconsule uires suas confirmauerant. quin etiam Ithacius ab his quasi perturbator ecclesiarum reus postulatus, iussusque per atrocem exsecutionem deduci trepidus profugit ad Gallias; ibi Gregorium praefectum adiit. qui compertis quae gesta erant, rapi ad se turbarum auctores iubet ac de omnibus ad imperatorem refert, ut haereticis uiam am biendi praecluderet. sed id frustra fuit, quia per libidinem et potentiam paucorum cuncta ibi uenalia erant. igitur haeretici suis artibus, grandi pecunia Macedonio data, optinent, ut imperiali auctoritate praefecto erepta cognitio Hispaniarum uicario deferretur; nam iam proconsulem habere desierant; missique a magistro officiales, qui Ithacium tum in Treveris agentem ad Hispanias retraherent. quos ille callide frustratus, ac postea per Britannium episcopum defensus illusit. iam tum rumor incesserat clemens, Maximum intra Britannias sumpsisse imperium ac breui in Gallias erupturum. ita tum Ithacius statuit, licet rebus dubiis, noui imperatoris aduentum exspectare; interim sibi nihil agitandum.

Zos. 4, 35, 3. Es poco probable que Itacio conociera que Máximo se había hecho bautizar poco antes de su alzamiento, como recuerda el usurpador en su epístola a Siricio algunos años más tarde: Coll. Avell. 40,1. Vid. infra.

10 Zos. 4,35,1; Amm. 29,5; 6; 21.

11 Sulp. Sev. Chron. 2, 48, 2.

12 Prisc. Tract. 1, 20, 23. Según Isidoro - Isid. De uir. ill., 2,Itacio Claro es autor de un libro apologético (librum sub apologetici specie) no conservado, en el cual acusaba a Prisciliano de maleficio y de conducta licenciosa. Jerónimo y Sulpicio Severo pudieron conocer el Apologético de Itacio, cf. Hier. De uir. ill., 121; Id., ep., 75, 3, Id., Comment. in Esaiam, 17, 64, 4-5.

13 Sulp. Sev. Chron. 2, 47, 1: igitur post multa inter eos nec digna memoratu certamina apud Caesaraugustam synodus congregatur... in absentes tamen lata sententia damnatique Instantius et Saluianus episcopi, Helpidius et Priscillanus laici. Exemp. profes., Chadwick 1976, según un rescripto de Graciano ${ }^{14}$ y tanto Dámaso de Roma como Ambrosio de Milán se habían negado a recibirlos con ocasión de su viaje a Italia. ${ }^{15}$ Esta parte de las preces era decisiva.

Máximo dispuso de pruebas de que la postura de Itacio era la sostenida por destacados obispos en Hispania, Galia e Italia y respondía a una forma más jerárquica y organizada de concebir la función episcopal. Itacio pudo presentar ante Máximo las actas del concilio de Caesaraugusta, celebrado en torno al 379/380, pues, además de estar presente en sus sesiones, se había encargado de difundir los acuerdos de la asamblea entre las iglesias. ${ }^{16}$ En él habían participado 12 obispos entre los cuales figuraban los galos Fitadio, identificado con Febadio de Agen ${ }^{17}$ y Delfino, obispo de Burdeos, residencia del vicario de la Galia meridional, además de Hidacio de Mérida, capital del vicariato de las Hispanias. ${ }^{18}$ La petición de Itacio venía avalada por Britanio de Tréveris, de manera que atenderla podía proporcionar al usurpador el apoyo del obispo y de las iglesias de la ciudad. Después de su proclamación en Britania en la primavera de $383,{ }^{19}$ y tras la eliminación del emperador legítimo cerca de Lyon por el magister equitum de Máximo, Andragacio, ${ }^{20}$ Máximo necesitaba asentar su posición en las instituciones en un momento crítico, sumar al golpe partidarios en Tréveris y ganar apoyos en las provincias de Occidente. El sostén episcopal era una parte imprescindible para consolidar su poder en un contexto de inestabilidad. De hecho, hasta 384 no fue admitido como colega en el Imperio por Teodosio y Valentiniano y solo en 386 obtuvo el reconocimiento pleno. ${ }^{21}$ Por otra parte, la negativa de Dámaso de Roma y Ambrosio de Milán a recibir a Prisciliano y sus partidarios y, en consecuencia, a otorgarles cartas de comunión que probasen su ortodoxia pudo influir en la decisión de Máximo, teniendo en cuenta que en 380 Dámaso había sido incluido por Teodosio en la constitutio Cunctos populos (CTh 16,1,2) como referente de ortodoxia. ${ }^{22}$ De Ambrosio pudo obener información directa sobre el conflicto. En efecto, la primera embajada de Ambrosio a Tréveris en representación de la corte milanesa

236, I. 70-71. Cf. Prisc., Tract., 2, 35; Id., Tract., 2, 39; Id., Tract., 2, ibid., 40; Id., Tract., 2, ibid., 42, donde se afirma que ni Prisciliano ni ninguno de los suyos fueron condenados en el concilio.

14 Sulp. Sev. Chron. 2, 47, 6: igitur post multa et foeda certamina Ydacio supplicante elicitur a Gratiano tum imperatore rescriptum, quo uniuersi haeretici excedere non ecclesiis tantum aut urbibus, sed extra omnes terras propelli iubebantur. Prisc. Tract., 2, 40-41: dissimulatis nominibus nostris.

15 Sulp.Sev. Chron., 2, 48, 4: Damasus [...]ne in conspectum quidem admissi sunt; Ibid. 5: regressi Mediolanum atque aduersantem sibi Ambrosium reppererunt; Hydat. Cont. Chron. Hieron. a. 386, 13.

16 Sulp. Sev. Chron. 2, 47,3: atque id Ithacio Sossubensi episcopo negotium datum, ut decretum episcoporum in omnium notitiam deferret.

17 Aginum. Duchesne 1915, II/2: 60.

18 Rodríguez 1981, 17; Escribano Paño 2002, 109-111.

19 Vid. sobre la usurpación de Máximo: Palanque 1929, 1965; Ensslin1930; Casey 1979; Baldus 1984; Rogers 1997; Raschle 2005; Errington 2006, 31-37; Lunn-Rockliffe 2010; Kelly 2014; Omissi 2018.

20 Aur. Vict. Epit. 47,7; Zos. 4, 35, 3-6. Vid. también Ruf. Hist. eccl. 11-14; Soc. Hist. eccl. 5,11, 7; Soz. Hist. eccl. 7,13, 8-9; Hier. ep. 60,15; Chron. Gall. I, 629, 3 y 646, 9; Marcell. Chron. II, 61, 383, 3. Sobre las distintas versiones en torno a su muerte vid. Cameron 2007. Tras la caída de Máximo, Teodosio hizo trasladar sus restos a la iglesia de los Santos Apóstoles en Constantinopla (Croke 2010, 253-254).

21 Vera 1975; Errington 2006, 32-34.

22 Errington 1997. 
tuvo lugar en el otoño del 383.23 Máximo pudo conocer de primera mano la posición mantenida entonces por el influyente obispo de Milán, al que, según el Liber ad Damasum, Hidacio de Mérida había consultado antes de dirigir al emperador Graciano su libellus contra los falsos obispos y maniqueos. ${ }^{24}$ Por otro lado, el estado de opinión de las iglesias itálicas no era favorable a Prisciliano y sus seguidores. Entre el 380 y el 390 Filastrio de Brescia los describe con trazos sospechosos en su catálogo de herejías, recogiendo la opinión que circulaba en los medios eclesiásticos itálicos. Termina su referencia a los maniqueos señalando que muchos de ellos se escondían en Hispania y en Aquitania y cautivaban a muchos diariamente con su engaño. ${ }^{25}$ Agustín pensaba que Filastrio estaba aludiendo a los priscilianistas. ${ }^{26}$

Según Sulpicio Severo, Itacio con sus preces plenas inuidiae et criminum convenció a Máximo (quibus permotus imperator). ${ }^{27}$ La referencia a crimina denotaría que la acusación de prácticas mágicas ya formó parte del dosier entregado. Sin embargo, las actas del concilio de Caesaraugusta censuraban prácticas vinculadas a la magia, el maniqueísmo y la lectura de apócrifos, pero no recogían la condena nominal de Prisciliano y sus seguidores. Ante la duda, Máximo prefirió delegar en un concilio para recomponer la unidad religiosa. Al hacerlo, el Augusto de Tréveris que, como todos los usurpadores, una vez conseguido el poder, estaba deseoso de legitimidad, se mostró escrupuloso con la reglamentación legislativa, según la cual las causas de religión eran competencia exclusiva del foro eclesiástico. Así lo habían establecido Constancio II (CTh 16, 2, 12. 355), Valentiniano I en un rescripto no conservado pero evocado por Ambrosio de Milán en su epístola 75 de $386^{28}$ y la ley de Graciano del 375 conservada en CTh 16, 2, 23. El consejo de Ambrosio, frente a Itacio, que defendía el juicio ante el prefecto del pretorio o ante el tribunal imperial, pudo ser decisivo en la defensa del foro eclesiástico, si atendemos a su respuesta a Valentiniano II cuando este le ordenó comparecer en la corte para una certatio con Mercurino Auxencio en 386. En ese momento invocó el mencionado rescripto de Valentiniano I, que había atribuido a los sacerdotes en exclusiva el derecho a juzgar a otros sacerdotes en materia de fe: pater tuus dicebat: non est meum iudicare inter episcopos. ${ }^{29}$ Por otro lado, la emulación pudo influir en la decisión de Máximo: Teodosio, poco después de ingresar en Constantinopla, había convocado el primer concilio de la ciudad para hacer visible su apoyo a los obispos nicenos. ${ }^{30} \mathrm{Y}$ no hay que olvidar que a la vez que atendía las peticiones de Itacio de intervenir en una controversia eclesiástica, Máximo estaba pendiente del resultado de sendas embajadas enviadas a Milán y Constantinopla ${ }^{31}$ buscando, en un caso, la primacía en Occidente,

\footnotetext{
23 Ambros. ep. 30, 7. McLynn 1994, 160-164. Duval 2002.

24 Prisc. Tract., 2, 40-41. Cf. Sulp. Sev. Chron. 2, 47, 6.

25 Philastr. Diuer. heres. liber, 61; 84.

6 Aug. De haeres. 70,1.

7 Sulp. Sev. Chron. 2, 47, 2

28 Ambr. ep. 75, 2: Augustae memoriae pater tuus non solum sermone respondit sed etiam legibus sanxit: in causa fidei uel ecclesiastici alicuius ordinis eum iudicare debere qui nec munere impar sit nec iure

29 Ambros. ep. 75, 4 y 5. Barnes 2002; Lizzi Testa 2009.

30 Errington 1997, 41-47.

31 Ambr. ep. 30. 7; Zos. 4.37.1. Them. Or. 18, 220c-221a. Errington 2006, 32; McEvoy 2013, 86-92.
} dissimilis. con el traslado del adolescente Valentiniano II y su madre Justina a la corte de Tréveris, y en otro su reconocimiento por el Augusto de Oriente. Dada la centralidad que había ido ganando la liturgia cristiana en la autorrepresentación del emperador, ${ }^{32}$ Máximo también necesitaba rodearse de obispos fieles y encontró la ocasión de elegir la que le pareció la alianza episcopal más fuerte.

La sede escogida para la reunión no fue hispana, sino gala, Burdeos, residencia del vicario de la Galia meridional. Intereses regionales y políticos se conjugaron con la conveniencia de asegurar el resultado. Del mismo modo que tras la eliminación de Graciano el 25 de agosto de 383 Máximo se apresuró a poner la prefectura de las Galias bajo su control y procedió a la purga de los funcionarios fieles a Graciano, ${ }^{33}$ también procuró distanciarse del emperador asesinado, cuya última intervención en la causa priscilianista había sido la orden de transferir la cognitio de Itacio al vicario de las Hispanias. ${ }^{34}$ Se trataba de debilitar la legitimidad de su antecesor y enemigo atacando su política religiosa. Burdeos presentaba otras particularidades. Su titular, Delfino, había participado en el concilio de Caesaraugusta y era un obispo prestigioso. Pertenecía al círculo aquitano de ascetas en el que hay que incluir a Sulpicio Severo, a Didier - el destinatario de la Vita Martini-, a Paulino de Nola y a Exuperio, futuro obispo de Toulouse. ${ }^{35}$ Pero, sobre todo, Delfino había mantenido desde el concilio de Caesaraugusta una actitud abiertamente hostil hacia los priscilianistas: había expulsado de su ciudad a los líderes Prisciliano, Instancio y Salviano, de paso en Burdeos en su camino hacia Roma. Y una razón más, además de su emplazamiento como terminal de la vía Emerita-Burdigala, se sumó a la elección: los heréticos contaban con renombrados y aristocráticos seguidores en la zona y el concilio podía contribuir a estigmatizar la herejía en su territorio. Eucrocia, mujer del retor, abogado y beneficiario de oficios palatinos Tiro Delfidio, ${ }^{36}$ había acogido a Prisciliano, Instancio y Salviano en sus posesiones aquitanas tras el rechazo de Delfino y, junto a su hija Prócula, se había sumado al séquito de Prisciliano cuando este retomó la ruta hacia Italia. ${ }^{37}$ Posteriormente, en los juicios de Tréveris, Eucrocia fue condenada a morir por la espada, lo que denotaría su compromiso con la secta. ${ }^{38}$

A finales de 383 o ya en 384 Máximo dio instrucciones escritas al prefecto del pretorio de las Galias y al vicario de las Hispanias para que hicieran comparecer ante el concilio reunido en Burdeos a todos aquellos a los que illa labes había envuelto. ${ }^{39}$ Se trataba de evitar cualquier defecto de procedimiento, es decir, impedir la estrategia de la absentia deliberada que habían utilizado los priscilianistas con ocasión del concilio de Caesaraugusta para evitar ser condenados

32 McLynn 2004.

3 Ambr. ep. 30, 11.

34 Sulp. Sev. Chron. 2, 49, 2.

Fontaine 1967, 19.

PLRE, I, 246, Attius Tiro Delphidius.

Sulp. Sev. Chron. 2, 48,1.

Sulp. Sev. Chron. 2, 51,2

Sulp. Sev. Chron. 2, 49, 2: ... quibus permotus imperator, datis ad praefectum Galliarum atque ad uicarium Hispaniarum litteris, omnes omnino, quos labes illa inuoluerat, deduci ad synodum Burdigalensem iubet. 
nominalmente. Entonces se habían apoyado en el dictamen de Dámaso de Roma. ${ }^{40}$

La información sobre el desarrollo del Reichssynode es muy escueta y prácticamente se limita a la que recoge Sulpicio y una breve referencia de Próspero de Aquitania. ${ }^{41} \mathrm{Se}$ ignora el número total de obispos asistentes, en cuya selección debieron de intervenir Itacio y Britanio: además de ellos estuvieron presentes con seguridad dos obispos que ya antes habían tomado parte contra Prisciliano y sus seguidores en el concilio de Caesaraugusta, Hidacio de Mérida y el obispo de la ciudad, Delfino. Es probable que participara Febadio de Agen, también presente en el concilio hispano, con amplia experiencia en la lucha contra los heréticos: era el más antiguo en el episcopado y defendido la ortodoxia frente a los arrianos. Había sufrido exilio, al igual que Hilario de Poitiers, ${ }^{42}$ tras el concilio de Béziers (356). Tomó parte también en el concilio de Rímini (359), sin lograr imponer sus tesis, y presidió, probablemente por razón de antigüedad, el concilio galo de Valence (concilium Valentinum en 374). ${ }^{43}$ También Martín de Tours estuvo presente en Burdeos, según indica Hidacio en su Crónica. ${ }^{44}$

Sin embargo, el concilio de Burdeos presenta una particularidad, y es que fue interrumpido por la negativa de Prisciliano a ser oído por los que le parecieron iudices suspecti, después de que Instancio expusiera su causa y fuera declarado indigno del episcopado. La agenda de sus antagonistas se estaba imponiendo, comprendió que iba a ser condenado nominalmente ${ }^{45}$ y apeló al emperador: ne ab episcopis audiretur, ad principem prouocauit. Todos los obispos reunidos estuvieron de acuerdo en aceptar el rechazo y transferir el asunto al emperador. Así lo lamenta Sulpicio cuando atribuye a la inconstantia nostrorum haber permitido (permisit) la transferencia a la corte imperial de tam manifestis criminibus en lugar de pronunciar sentencia contra Prisciliano, aunque la rechazase, o delegar en otros obispos. ${ }^{46} \mathrm{En}$ esta autorización, la intervención de Itacio persuadiendo a sus colegas debió de ser decisiva, si se tiene en cuenta su actuación previa y posterior.

La investigación moderna, desde Babut a Girardet, ha mostrado su extrañeza por la que parece una iniciativa desconcertante. ${ }^{47}$ Las acusaciones durante las sesiones conciliares no solo habían tratado de la divergencia herética, incluyeron también manifesta crimina, en palabras de Sul-

40 Prisc. Tract. 2, 35: tua potissimum epistola contra improbos praeualente, in qua iuxta euangelica iussa praeceperas, ne quid in absentes et inauditos decerneretur.

41 Sulp. Sev. Chron. 2, 49, 2-3; Prosper. Aquit. Epit. Chron. n. 1187. a. 385. MGH aa 9, Chronica minora 1, 462.

42 Hieron. De script. eccl. 100.

43 Fue corresponsal de Ambrosio (ep. 72) y citado por Jerónimo entre sus uiri illustres (108), qiue dice que era muy anciano en 392. Escribió un tratado contra los arrianos editado por A. Durenges, Le livre de saint Fhebade contre les Arriens, Agen 1927. Gaudemet 1977,103.

44 Hyd. Chron. a. 386, 13.

45 Prosper. Aquit. Epit. Chron. n. 1187. a. 385, MGH aa 9, Chronica minora 1, 462: Priscillianus in sinodo Burdigalensi damnandum se intellegens.

46 Sulp. Sev. Chron. 2, 49,3. Cf. Prosper. Aquit. Epit. Chron. n. 1187. a. 385, MGH aa 9, Chronica minora 1, 462: ad imperatorem prouocauit; Hyd. Chron. 13 b: appellat ad Caesarem, quia in Gallis hisdem diebus potestatem tyrannus obtinebat imperii.

47 Babut 1909,180-181; Stockmeier 1967; Girardet 1974; Escribano Paño 1994, 393-416. picio, lo que tratándose de sospechosos de maniqueísmo remite al maleficium. ${ }^{48}$ No era lo mismo arriesgarse a perder la sede episcopal, los bienes patrimoniales y los derechos testamentarios, que eran las penas previstas en las leyes contra los maniqueos, ${ }^{49}$ que perder la vida, pues el maleficium formaba parte de los crimina más atroces castigados con la muerte y las sentencias del tribunal imperial eran inapelables. ${ }^{50}$ Ya antes del concilio de Caesaraugusta Itacio había lanzado contra los priscilianistas el novum dictum de haber practicado encantamientos mágicos para santificar o consagrar las primicias de los frutos, así como invocaciones demoníacas al sol y a la luna con la degustación y el empleo de un ungüento maldito, cuya eficacia disminuía en relación con los eclipses y los ciclos. ${ }^{51}$ El mismo Prisciliano había reconocido poseer un amuleto con el nombre de dios en hebreo, latín y griego y la representación de un león. ${ }^{52}$ Prisciliano parecía conocer la reciente legislación teodosiana contra los maniqueos que simulaban ser ascetas, ${ }^{53}$ incluso había defendido la tortura y la muerte por la espada para los maniqueos. ${ }^{54}$ Sin embargo, apeló al emperador, de lo que cabe deducir que confiaba en tener un arbitraje o un juicio más equitativo en la corte.

Según Sulpicio Severo, no solo Prisciliano, el único en formular la prouocatio ad principem, sino todos los implicados en la causa fueron conducidos ante el rex y a estos les siguieron los acusadores Hidacio e Itacio de los que el cronista galo dice que combatieron - certassent- con más studio uincendi del que convenía. El debate se trasladó a la corte de Tréveris, que se convirtió en un espacio de confrontación entre obispos tratando de orientar la decisión del emperador. La estrategia de Itacio de mantener la acusación de herejía e incriminar como socius o discipulus de Prisciliano a cualquiera que mostrase gusto por la lectura de las escrituras o los ayunos, incluido el uir plane apostolis conferendus Martín de Tours, condujo al juicio imperial. ${ }^{55}$

48 Mos. et Rom. legum collatio, 15, 3, 4-5. La asociación del maniqueísmo con el maleficium está presente en el rescripto de Diocleciano contra los maniqueos (302) (Rees 2004, 174-175), que tuvo una influencia decisiva en la legislación antiherética posterior.

49 CTh 16,5,3. 372; 5,7. 381; 5,9. 382. Kaden 1953; Beskow 1988. Escribano Paño 2011; 2012.

50 Taubenschlag 1928; Rives 2003.

51 Prisc. Tract. 1, 20, 23: inter quae tamen nouum dictum et non dicam facto, sed et relatione damnabile nec ullo ante hoc heretico auctore prolatum sacrilegii nefas in aures nostras legens Ithacius induxit magicis praecantationibus primitiuorum fructuum uel expiari uel consecrari oportere gustatus unguentumque maledicti Soli et Lunae, cum quibus deficiet, consecrandum.

52 Prisc. Tract. 1, 31, 26. Breyfogle 1995, 449.

53 CTh 16,6,9. 382: ceterum quos encratitas prodigiali appellatione cognominant, cum saccoforis siue hydroparastatis refutatos iudicio, proditos crimine, uel in mediocri uestigio facinoris huius inuentos summo supplicio et inexpiabili poena iubemus adfligi, manente ea condicione de bonis, quam omni huic officinae imposuimus, a latae dudum legis exordio...

54 Prisc. Tract. 1, 26,22: anathema sit qui Manetem et opera eius doctrinas adque instituta non damnat; cuius peculiariter turpitudines persequentes gladio, si fieri posset, ad inferos mitteremus ac si quid est deterius gehennae tormentoque peruigili, ubi neque ignis extinguitur neque uermis emoritur. Quorum diuino iudicio ut inpuritas non lateret, etiam saecularibus iudiciis mala prodita sunt.

55 Sulp. Sev. Chron. 2, 50,1. Prinz 1982, 21 y 28, señala las afinidades ascéticas entre Prisciliano y Martín y apunta que Sulpicio pudo silenciar algunos hechos que le implicaban. Esta tesis ya fue defendida por Babut 1912, 154-156. 
En efecto, la corte se sintió concernida por la naturaleza de las acusaciones y las presiones. Era una elección política arriesgada juzgar a clérigos por maniqueos sobre los que, además, pesaban acusaciones de magia. Sin embargo, los recientes juicios antioquenos por magia en la corte de Valente $^{56}$ hacían ineludible responder según las previsiones legislativas que prohibían las prácticas mágicas y las penalizaban con la muerte. ${ }^{57}$ Por otro lado, la legislación teodosiana preveía la apertura de juicio contra maniqueos que se hacían pasar por ascetas en la constitutio de 382 dirigida al prefecto del pretorio Floro. ${ }^{58}$

Sulpicio establece una dualidad entre quos causa inuoluerat y los accusatores. A partir de entonces el juego político en el entorno imperial se polarizará entre los obispos partidarios del juicio imperial por maniqueísmo y los que, considerando heréticos a los priscilianistas, lo rechazaban, con las intervenciones decisivas de Martín de Tours y Ambrosio de Milán.

Por lo que respecta a Martín, trasladado a la corte de Tréveris, el obispo asceta se enfrentó a Itacio rogándole que desistiera de su acusación. Al mismo tiempo pedía a Máximo que se abstuviera de derramar sangre, es decir, que renunciara al juicio por magia, con dos argumentos: el primero, el concilio de Burdeos ya los había declarado heréticos, con lo cual bastaba con expulsarlos de las iglesias. El segundo era de procedimiento: la intervención de un juez secular en una causa eclesiástica contravenía el ordenamiento legislativo y canónico (saeuum esse et inauditum nefas, ${ }^{59}$ ut causam ecclesiae iudex saeculi iudicaret). Martín trataba de impedir cualquier intervención de la instancia imperial en la causa, temeroso del resultado. Máximo, por estrategia o convicción, o por las dificultades que conllevaba el proceso acusatorio por maniqueísmo - era difícil encontrar las pruebasdudó y aplazó la cognitio (dilata cognitio) mientras Martín estuvo en Tréveris, comprometiéndose antes de su partida a que no se decidiría nada cruento.

Pero después, el emperador, deprauatus por los obispos Magno y Rufo, se apartó de los consejos más moderados et a mitioribus consiliis deflexus - y permitió iniciar la causa (permisit causam) al prefecto del pretorio Evodio. ${ }^{60}$ En los Dialogi Sulpicio Severo insiste en la inspiración episcopal de su decisión (Imperator Maximus imperator, alias sane bonus, deprauatus consiliis sacerdotum), aunque también afirma que Máximo era proclive a complacer a los obispos

56 Amm. 29,1,4-29,2,28; 31,14,8-9; Eunap. VS 7,6,3-7; Zos. 4,14,1-15,3; Lib. Or. 1,171-173; Epit. 48,3-4; Philostorg. Hist. eccl. 9,15; Socrat. Hist. eccl 4,19,1-7; Sozom. Hist. Eccl. 6,35,1-11; Joh. Ant. Fr. 184, 2; Theoph.a.m. 5865, 5867; Zon. 13-16; Cedrenus, 548.

57 Wiebe 1995; Neri 2014; Kahlos 2016

58 CTh 16,5,9. 382: sublimitas itaque tua det inquisitores, aperiat forum, indices denuntiatoresque sine inuidia delationis accipiat.

59 Cf. Pacat. Pan.lat 2 [12], 31,3: tecum (Theodosius) fas; secum (Maximus) nefas.

60 Sulp. Sev. Chron. 2, 50, 2: Martinus apud Treueros [...]non desinebat increpare Ithacium, ut ab accusatione desisteret, Maximum ora re, ut sanguine infelicium abstineret: satis superque sufficere, ut episcopali sententia haeretici iudicati ecclesiis pellerentur; saeuum esse et inauditum nefas, ut causam ecclesiae iudex saeculi iudicaret. denique quoad usque Martinus Treueris fuit, dilata cognitio est: et mox discessurus egregia auctoritate a Maximi elicuit sponsionem, nihil cruentum in reos constituendum. sed postea imperator per Magnum et Rufus deprauatus et a mitioribus consiliis deflexus causam praefecto Euodio permisit, uiro acri et seuero. (ille, licet episcopis nimio fauore esset obnoxius). ${ }^{61}$ Desconocemos las sedes de Magno y Rufo. Seguramente fueron requeridos y consultados como asesores - la práctica era frecuente desde que Constantino abrió la corte a los obispos $-{ }^{62}$ y se alinearon con Itacio e Hidacio, estos últimos como acusadores, los otros como consiliarii, frente a los más indulgentes (mitiores).

En la Vita Martini, antes de narrar la escena del banquete y la profecía de la caída de Máximo, ${ }^{63}$ escena que hay que situar en el contexto de esta primera visita de Martín a la corte, ${ }^{64}$ Sulpicio Severo presenta a los obispos en foedus con el emperador y los acusa de haber transformado la dignidad sacerdotal en clientela regia. ${ }^{65}$

Desde entonces, Máximo formó un bloque con los itacianos, cuya separación seguramente le hubiese valido el aislamiento al perder el apoyo de la parte mayoritaria del episcopado galo, si no la acusación de tibieza ante la herejía y la magia. La respuesta imperial a la prouocatio de Prisciliano se sustanció, por consejo de los obispos, en la apertura de juicio público. Máximo no juzgó directamente, lo hizo el prefecto Evodio, con el obispo Itacio como acusador en el primer iudicium y el patronus fisci Patricio en el segundo, pero tras serle remitidos los gesta del proceso por el prefecto, donde constaba la confesión de maleficium por parte de Prisciliano inter iudicia ${ }^{66}$ y la consiguiente declaración de culpabilidad, estimó (censuit) que era preciso condenar a Prisciliano y sus partidarios a la pena capital, en estricta aplicación de la legislación para el crimen de magia y faltando al compromiso contraído con Martín. ${ }^{67}$

La retirada de Itacio pudo estar relacionada con la intervención de Ambrosio de Milán.

En efecto, la solidez de la alianza de Máximo con el episcopado partidario del juicio y de las sentencias se puso a prueba con ocasión de la segunda legatio de Ambrosio a Tréveris coincidiendo con la celebración del proceso, entre el otoño de 384 y la primavera de 385 , antes de abril, que conocemos por su epístola 30 a Valentiniano II (Maur. 24),

61 Sulp. Sev. Dial 2 (3), 11, 2-5; 12, 2-13.

62 Teja 2012.

63 Roberts 1995; Lizzi Testa 2008.

64 Fontaine 167-1969, 915.

65 Sulp. Sev. V. Mart. 20, 1: ...cum ad imperatorem Maximum, ferocis ingenii uirum et bellorum ciuilium uictoria elatum, plures ei diuersis orbis partibus episcopi conuenissent et foeda circa principem omnium adulatio notaretur seque degenere inconstantia regiae clientelae sacerdotalis dignitas subdidisset, in solo Martino apostolica auctoritas permanebat.

66 CA 40,4.

67 Sulp. Sev. Chron. 2, 50,3: is Priscillianum gemino iudicio auditum conuictumque maleficii nec diffitientem obscenis se studuisse doctrinis, nocturnos etiam turpium feminarum egisse conuentus nudumque orare solitum, nocentem pronuntiauit redegitque in custodiam, donec ad principem referret. gesta ad palatium delata censuitque imperator, Priscillianum sociosque eius capite damnari oportere. 2, 51, 1: Ceterum Ithacius uidens, quam inuidiosum sibi apud episcopos foret, si accusator etiam postremis rerum capitalium iudiciis adstitisset - etenim iterari iudicium necesse erat - subtrahit se cognitioni, frustra callidus iam scelere perfecto. ac tum per Maximum accusator apponitur Patricius quidam, fisci patronus. ita eo insistente Priscillianus capitis damnatus est, unaque cum eo Felicissimus et Armenius, qui nuper a catholicis, cum essent clerici, Priscillianum secuti desciuerant. Sobre el desarrollo de los juicios y su estructura según las interpretaciones de Babut, Ramos Loscertales, Stockmeier y Girardet vid. Escribano Paño 1988, 356-380; 1994, 393-416. 
donde daba cuenta de su misión. ${ }^{68}$ Las dudas sobre su autenticidad ${ }^{69}$ parecen superadas. ${ }^{70}$ Prescindiendo de los esfuerzos del obispo por magnificar su actividad diplomática, cuando en realidad él mismo ofrece evidencias de que las negociaciones entre Tréveris y Milan se producían al margen de su intervención, tanto en la primera como en la segunda embajadas ${ }^{71}$ la epístola reproduce los puntos conflictivos entre las dos cortes imperiales antes de que se produjese la crisis de las basílicas en Milán. Una parte de los estudiosos emplaza la segunda embajada de Ambrosio en 386 y la considera una reacción a la epístola que Máximo envió a Valentiniano después del conflicto entre el obispo y la corte de Milán a propósito del uso de las basílicas de la ciudad..$^{72}$ Esta propuesta de datación fue desarticulada por Duval ${ }^{73}$ con argumentos que compartimos. En el preámbulo de la carta Ambrosio alude a la falta de interés de la corte por conocer el resultado de su primera embajada y revela que la expositio de la segunda misión era iniciativa del mismo Ambrosio. ${ }^{74}$ La suposición de que Ambrosio había sido enviado por la corte de Milán a Tréveris tras recibir la carta de Máximo para desmentir en persona la persecución religiosa en Milán no parece compatible con el desinterés imperial que refleja el obispo en su misiva. Por otra parte, los asuntos tratados en la epístola 30 de Ambrosio no guardan relación alguna con las cuestiones planteadas por Máximo a Valentiniano. Por el contrario, Ambrosio, en la epístola 76 (Maur. 20) a Marcelina, escrita después de la Semana Santa de 386, se refiere a hechos recogidos en la epístola 30,75 por lo que no puede ser posterior. En otro orden, surgen algunas dudas. El penúltimo parágrafo de la carta implica que Ambrosio pensó que no podría salir vivo de Tréveris. ¿Cómo podría temer por su vida en Tréveris - ... etsi me plerique insidias euasurum non crederent $-{ }^{76}$ el obispo cuya persecución en Milán había motivado la carta de Máximo a Valentiniano? Ambrosio atribuye a Dios omnipotente la conservación del regnum de Valentiniano ante el Augusto de Tréveris. ${ }^{77}$ ¿Es compatible esta afirmación de Ambrosio en 386 con el contenido de su epístola a Valentiniano y del sermo contra Auxentium, textos redactados en el mismo año? Creo que debe invertirse el orden cronológico de las

68 La segunda embajada de Ambrosio a Tréveris se ha emplazado entre 384 y 387. Vid. la lista de fechas propuesta en Duval 2002, especialmente 240-241, n. 13. Seguimos la datación de Barnes 2000, 293-295 y Dörner 2001, 237-242. La fecha de la ejecución de Prisciliano y sus seguidores oscila entre el 385 y 386: Girardet 1974; Chadwick 1976, 137; Birley 1983; Williams 1995; Burrus 1995, 47, 187; Rousseau 1996, 479.

69 Dörner 2001, 217-244; Liebeschuetz 2005, 350-351.

70 Mclynn, en prensa.

71 Ambr. ep. 30 (Maur. 24), 1; 7. Proulx 2010.

72 McLynn 1994, 217; Williams 1995, 224-232, entre otros.

73 Duval 2002.

74 Ambr. ep. 30 (Maur. 24), 1.

75 Ambr. ep. 76 (Maur. 20), 23: caueret tamen, ne ipse sibi tyrannum faceret, cui Deus aduersarium non excitauit. non hoc Maximum dicere, quod tyrannus ego sim Valentiniani, qui se meae legationis obiectu queritur ad Italiam non potuisse transire; Cf. Ambr. ep. 30 (Maur.24). 4: quoniam me lusistis! [...] quod si ego (Maximus) tunc temporis, quando uenisti, non essem retentus, quis mihi obstitisset et uirtuti meae?

76 Ambr. ep. 30 (Maur. 24), 12.

77 Ambr. ep. 30. (Maur. 24), 3: «Quia tunc inferiori pacem petebam, nunc ut aequali». - "Cuius» inquit «beneficio?»-Respondi: "Omnipotentis dei, qui Valentiniano regnum, quod dederat, reseruauit». cartas y datar la segunda embajada de Ambrosio y la epístola 30 en el otoño-invierno de 384/385, después del debate sobre el ara Victoriae y antes de la Semana Santa de 385. ${ }^{78}$ Era entonces cuando estaban desarrollándose los juicios de Tréveris contra los priscilianistas.

En efecto, en el colofón de la epístola, tras describir su poco diplomático encuentro con el usurpador con el fin de eliminar cualquier duda de colaboración con él, ${ }^{79}$ Ambrosio refiere al Augusto de Milán que se había abstenido de comulgar con aquellos obispos que estaban en comunión con Máximo o que pedían la muerte para los que denomina deuios licet a fide. Instigado por ellos, (commotus eis), Máximo le había ordenado abandonar Tréveris sine mo$r a .^{80}$ Además Ambrosio quiere poner de manifiesto en la epístola-informe su escasa influencia en la corte, pues no pudo evitar, dice, que el anciano obispo Higinio - que había formulado la primera denuncia de los priscilianistas y después los había recibido en comunión,$-{ }^{81}$ fuese conducido al exilio sine ueste, sine plumario, es decir, desprovisto de cualquier abrigo, pese a la mediación de Ambrosio ante el comes responsable de ejecutar la medida. ${ }^{82}$

Al calificar a los priscilianistas como disidentes de la fe deuii licet a fide-, Ambrosio emite un juicio de autoridad ${ }^{83}$ y los cataloga como heréticos, como había hecho durante la primera embajada, pero se distancia del juicio por maleficium y, en consecuencia, de la intromisión del emperador en una causa eclesiástica y, más aún, de la actuación de los obispos como acusadores en un juicio público. ${ }^{84}$

La alianza entre Máximo y los obispos, antes y después de las sentencias, comparece en el panegírico de Pacato en honor de Teodosio pronunciado ante el senado romano en 389. Al caracterizar a Máximo como un tirano avaro, cruel y, sobre todo, impío, un nuevo Phalaris, por oposición al pia-

78 La estancia de Ambrosio en Tréveris hay que situarla entre el final de la primera parte de los iudicia contra Prisciliano y sus seguidores, cuando Itacio era el acusador (Ambr. ep. 68 [Maur. 26], 3: sed uehementior facta est, posteaquam episcopi reos criminum grauissimorum in publicis iudiciis accusare, alii et urgere usque ad gladium supremamque mortem, alii accusationes huiusmodi et cruentos sacerdotum triumphos prouare coeperunt) y su partida antes de la primavera de 385 y el inicio de la crisis de las basílicas en Milán.

Mclynn (1994, 217-218), que data la segunda embajada de Ambrosio a Tréveris en 386, después de la crisis de las basílicas, y Liebeschuetz $(2005,351)$ consideran la epístola como una justificación apologética de Ambrosio ante el fracaso de su misión en Tréveris.

${ }_{80}$ Ambr. ep. 30,12: postea vero cum uideret me abstinere ab episcopis, qui communicabant ei, uel aliquos, deuios licet a fide, ad necem petebant, commotus eis iussit me sine mora regredi. Paulino en la Vita Ambrosii, 19,2 lo interpreta como la excomunión de Máximo por Ambrosio: Ipsum uero Maximum a communionis consortio segregauit...

81 Sulp. Sev. Chron. 2,47,1. Prisc. Tract. 2, 41, 3-7.

82 Ambros. ep. 30, 12: ego vero libenter, etsi me plerique insidias euasurum non crederent, ingressus sum iter, hoc solo dolore percitus, quod Hyginum episcopum senem in exsilium duci comperi, cui nihil iam nisi extremus superesset spiritus. Cum de eo conuenirem comites eius, ne sine ueste, sine plumario paterentur extrudi senem, extrusus ipse sum.

83 Además de su compromiso activo en la lucha contra la herejía arriana, había compuesto dos volúmenes De fide que entregó a Graciano en marzo de 380 (McLynn 1994, 102 ss.).

${ }^{84}$ Cf. Ambr. ep. 68, (Maur. 26), 3: sed uehementior facta est, posteaquam episcopi reos criminum grauissimorum in publicis iudiciis accusare, alii et urgere usque ad gladium supremamque mortem, alii accusationes huiusmodi et cruentos sacerdotum triumphos prouare coeperunt. 
doso Teodosio, dentro del esquema antitético del discurso, 85 alude a los juicios de Tréveris. Denuncia la amicitia del usurpador con antistites solo de nombre, pero en realidad satellites y carnifices. A estos los describe como delatores, calumniadores y responsables de la ruina, tortura y muerte de sus víctimas, entre ellas, la matrona Eucrocia, víctimas a las que considera inocentes (Obiciebatur enim atque etiam exprobatur mulieri uiduae nimia religio et diligentius culta diuinitas).$^{86}$ El panegirista subraya que después de manchar sus manos por el contacto con el castigo, los sacerdotes seguían oficiando (pollutas poenali contactu manus ad sacra referebant et caerimonias quas incestauerant mentibus etiam corporibus impiabant), lo que significa que los obispos mantuvieron el pacto con Máximo. El orador necesitaba distanciar al cristianísimo Teodosio de Máximo después de su caída, ${ }^{87}$ más aún si tenemos en cuenta que pudo darse una correlación entre la actuación del Augusto de Tréveris en defensa de la ortodoxia y su pleno reconocimiento por la corte de Constantinopla en $386 .{ }^{88}$

\section{LA FUNCIÓN RELIGIOSA IMPERIAL Y LA DISPUTA PRISCILIANISTA: LA INTERPRETACIÓN DE MÁXIMO}

Conocemos de primera mano el juicio de Máximo sobre las relaciones entre el emperador y los obispos y sobre su actuación en la causa priscilianista. La Collectio Avellana, compilada en Roma a mediados del s. $\mathrm{VI}^{89}$ conserva dos epístolas del usurpador, una dirigida a Valentiniano II y otra escrita al obispo Siricio de Roma. ${ }^{90}$ Las dos tratan de la intromisión del poder imperial en asuntos eclesiásticos desde la óptica del emisor y en ambas la lucha contra la herejía, como parte de la función imperial, es un asunto central. Fueron redactadas un año después de los juicios de Tréveris y después de que hubiese concluido la denominada crisis de las basílicas de Milán de abril de $386^{91}$ y antes de producirse

85 Pacat. Pan. Lat. 2 [12], 29, 4: hos ille Falaris in amicis habebat, hi in oculis eius atque etiam in osculis erant, nec iniuria, a quibus tot simul uotiua ueniebant: auaro diuitum bona, cruento innocentium poena, impio religionis iniuria. Aunque la impietas no era imputable a Máximo. Vid. Ziegler 1970, 74-85; Omissi 2018, 269-290, especialmente 280-283. Cf. Oros. Hist. 7,34,9.

86 Pacat. Pan. Lat. 2 [12], 29, 2.

87 Después de la caída de Máximo en 388 se produjo la rescissio de sus acta. Las constitutiones CTh 15,14 6. 388; 7. 388 (Omne iudicium, quod uafra mente conceptum iniuriam, non iura reddendo Maximus infandissimus tyrannorum credidit promulgandum, damnabimus $<$ Nullus igitur sibi lege, nullus iudicio blandiatiur); 8. 389, revocaban los honores y dignitates concedidos por el usurpador y abolían sus leges et iudicia. No obstante, Ambrosio en el De Obitu Theodosii (5) y Pacatus en su panegírico (Pan. Lat. 2 [12], 45, 5-6) se refieren a la amnistía dada por Teodosio en 388 eximiendo a muchos de restituir los salarios recibidos bajo el usurpador. Por otra parte, los compiladores del Codex Theodosianus conservaron algunas leyes de Máximo eliminando su nombre de la inscriptio (CTh 9.36.1 (385); 6.28 .4 [ 387]).

${ }_{88}$ Cf. Barnes 2000, 298, que relaciona el reconocimiento de Máximo por Teodosio con el apoyo de Valentiniano II a los arrianos de Milán.

89 Lizzi 2014; Blair-Dixon 2007.

90 Documentos 39 y 40 en la edición de Otto Günther, Epistulae imperatorum pontificium aliorum inde ab a. CCCLXVII ad a. DLIII datae Avellanae quae dicitur collectio, I. Prolegomena. Epistulae I-CIV, II. Epistulae CV-CCXXXXIIII. Appendices. Indices, Pragae-Vindobonae-Lipsiae, Tempsky-Freytag, 1895-1898, CSEL 35, I, 88-90. Hemos desarrollado estas ideas en Escribano Paño 2019, 50-85.

91 Williams 2017, 214-286. la invasión de Italia (387). En la primera, además de censurar la política religiosa de Valentiniano II dentro de una estrategia de deslegitimación de su rival en Occidente, ${ }^{92}$ Máximo ofrecía su visión personal sobre cómo debe desempeñar un buen príncipe su función religiosa, en particular se refería al papel que debe jugar el emperador en los conflictos eclesiásticos. Máximo instaba al Augusto de Milán a no interponerse (neque te medius interseras), de manera que fuesen los que disentían de la catholica ecclesia por su interpretatio arriana los que enmendasen su desviación..$^{93}$ En contra de lo que había pretendido Valentiniano II, presentándose como árbitro en la certatio entre Mercurino Auxencio y Ambrosio, el emperador no debía intervenir en las disputas heréticas y debía dejar en manos de sacerdotes e iglesias católicas su resolución.

Máximo repetirá el mismo argumento en la epístola dirigida el mismo año a Siricio de Roma. La carta respondía a una consulta de Siricio sobre cierto Agroecio, que había sido promocionado al grado de presbítero de manera irregular. Máximo declara que son los sacerdotes católicos los que deben juzgar. ${ }^{94}$ "¿Qué mayor respeto podría yo mostrar a nuestra religión católica?» se pregunta el Augusto de Tréveris retóricamente. En consecuencia, se muestra dispuesto a delegar en los obispos para que deliberen en concilio y deja en sus manos decidir la elección de la sede del conuentum y si la convocatoria debía incluir a los prelados de las Galias o solo a los de las Cinco provincias, en alguna de cuyas ciudades debía de haberse producido la irregular promoción.

Probablemente Siricio utilizó el asunto de Agroecio (conmemoras) como pretexto para interesarse por la situación del clero en la Galia tras la condena a muerte Prisciliano en juicios en los que habían actuado obispos como acusadores. En efecto, el ejemplo de Ambrosio al negarse a comulgar con aquellos obispos que estaban en comunión con Máximo o que pedían la muerte para los priscilianistas, pudo ser imitado por otros. Se censuró la actuación de Itacio durante el juicio tras la muerte del heresiarca. Máximo de nuevo delegó en un concilio reunido en Tréveris en 386 que concluyó que Itacio no era culpable. Solo un obispo, Teógnito, de sede desconocida, se había separado de su comunión. Martín de Tours, que al principio se resistía a comulgar con los obispos que apoyaban a Itacio, acabó cediendo a cambio de que el emperador ordenase regresar a los tribunos summa potestate armatos, que había enviado a Hispania para buscar heréticos, detenerlos y confiscar sus bienes. La recuperación de la concordia episcopal se hizo visible en un acto religioso solemne en la capital imperial: Martín participó en la elección de Félix como sucesor de Britanio, muerto en mayo de 386, para la sede de Tréveris y entró en comunión con los

92 Construir la legitimidad imperial sobre la destrucción de la legitimidad del rival había sido una estrategia practicada desde Augusto. En el s. IV fue Constantino el más hábil destructor de la imagen política de sus rivales Majencio y Licinio, después imitado por sus sucesores. Vid. Humphries 2008.

${ }_{93}$ CA 39,8: neque te medius interseras, cum fas sit iustius, qui a catholica ecclesia Arrianorum interpretatione discesserint, errorem suum uera religione mutare quam recte sentientibus suam immittere prauitatem.

${ }_{94}$ CA 40, 2: ...ceterum de Agroecio, quem indebite ad presbyterii gradum conscedisse commemoras. quid religioni nostrae catholicae possum praestare reuerentius, quam ut de hoc ipso, cuiuscemodi esse uideatur, catholici iudicent sacerdotes? 
obispos galos reunidos para la ocasión (Huius diei communionem Martinus initiit). ${ }^{95}$

Siricio pudo ver en esta situación de breve y leve discordia la ocasión para dirigirse en términos diplomáticos a Máximo. Incluso, como en el caso reciente de Himerio de Tarragona, ${ }^{96}$ es posible que la consulta estuviese relacionada con la petición o denuncia recibida de algún prelado galo. Agroecio podría haber sido uno de los promocionados irregularmente por los itacianos. La diócesis de quinque prouinciae o Viennensis, incluía Aquitania secunda, con Burdeos como metrópoli, ${ }^{97}$ cuyo obispo Delfino había sido especialmente beligerante con los priscilianistas en el pasado reciente, según se ha comentado. ${ }^{98}$

En la misma epístola de respuesta Máximo desarrollaba su visión sobre la misión imperial en relación con la fides catholica: debía permanecer illaesa et inuiolabilis, con todos los obispos en concordia (concordantibus uniuersis sacerdotibus) y sirviendo a dios. Cualquier dissenssio debía ser eliminada. ${ }^{99}$ Desde estas convicciones, refería al obispo de Roma los términos estrictamente técnicos de su intervención en la causa priscilianista. En efecto, el Augusto de Tréveris se distancia de la condena, a la vez que defiende su licitud. Ante Martín, Máximo había utilizado el argumento de que los heréticos habían sido condenados regularmente en juicios públicos (haeretici iure damnati more iudiciorum publicorum) y no por instigación de los obispos. ${ }^{100}$ En la misma línea, en la epístola a Siricio declara que el crimen que se había establecido recientemente (proxime) que habían cometido los maniqueos no se basaba en argumentos o en dudosas o inciertas sospechas, sino en su propia confesión inter iudicia. Máximo prefiere que Siricio conozca los detalles del crimen a partir de los gesta que adjunta, mejor que por su boca, pues dice no poder hablar sin rubor, porque eran turpia en su realización, pero también foeda para ser dichos. ${ }^{101}$ Como se ha señalado, el crimen confesado era maleficium. ${ }^{102}$ Los gesta judiciales reproducían la confesión, demostraban que eran maniqueos y habían sido condenados por prácticas mágicas y, sobre todo, probaban que Máximo no había actuado como iudex, ni se había interpuesto en una causa eclesiástica. ${ }^{103}$ El Augusto de Tréveris se mostraba subordinado a la autoridad del obispo de Roma, enemigo de la división entre los sacerdotes y respetuoso con las decisiones episcopales.

\section{Sulp. Sev. Dial 3, 12-13.}

96 Siric. ep. 1,1. Ante el clima de división en las iglesias hispanas, Himerio había consultado a Dámaso de Roma. Cuando la carta llegó a su destino, Siricio había sucedido a Dámaso, muerto el 11 de diciembre de 384. Callam 1980, 25-26 y Sardella 1995, sospechan la proximidad del obispo hispano a las posiciones rigoristas lo que explicaría su ausencia del concilio de Caesaraugusta de 380. Vid. Chadwick 1976, 236237; Vilella 2004; Hornung 2015; Ferreiro 2015.

97 CTh 16,10,15. 399. Macrobio uicario Hispaniarum et Procliano uicario quinque prouinciarum. Sobre la reorganización administrativa del territorio bajo el control de Máximo Vid. Harries 1978, 37

98 Sulp. Sev. Chron. 2,48,1.

99 CA 40, 3.

100 Sulp. Sev. Dial. 3,12,3.

101 CA 40,4.

102 Sulp. Sev. Chron. 2,50,3: is Priscillianus gemino iudicio auditum conuictumque maleficii nec diffitentem obscenis se studuisse doctrinis, nocturnos etiam turpium feminarum egisse conuentus nudumque orare solitum, nocentem pronuntiauit.

${ }_{103}$ Sobre el valor probatorio de las actas judiciales en los conflictos religiosos vid. Escribano Paño 2017.
No obstante reivindicaba su actuación ante Siricio, que no había cuestionado el comportamiento de Valentiniano II en Milán, pese a ser corresponsal de Ambrosio. ${ }^{104}$

Aunque, si hacemos caso a Sulpicio, la discordia episcoporum se prolongó en las Hispanias y las Galias ${ }^{105}$ durante largo tiempo, el valor probatorio de las actas debió de convencer a Siricio, enemigo de los maniqueos. ${ }^{106} \mathrm{El}$ Liber Pontificalis le atribuye el descubrimiento y exilio de maniqueos en Roma y la imposición de duras condiciones para obtener la reconciliación. ${ }^{107}$ Es probable que influyera en la promulgación de la constitutio CTh 16, 5, 18, de 17 de junio de 389 , dirigida al prefecto Albino, por la que Teodosio ordenaba expulsar a los maniqueos de Roma. El temor de Siricio a la presencia maniquea en la ciudad se deja notar en la epístola que Siricio escribió a Ambrosio en 393 para advertirle del peligro de Joviniano. Este se había trasladado a Milán con sus prosélitos tras ser condenado por un concilio en Roma. ${ }^{108}$

En el asunto priscilianista, la actitud de Siricio fue sobre todo reactiva. De hecho, solo diez años después de la caída de Máximo, el obispo Félix de Tréveris, en cuya ordenación habían intervenido Itacio y, probablemente, Hidacio, fue cuestionado por Siricio. Un concilio celebrado en Turín en 398 , reunido a petición de las provincias galas (postulatio), acordó recibir en comunión a aquellos obispos galos que decidiesen separarse de Felix. La decisión se tomaba de acuerdo con las cartas enviadas por Ambrosio y Siricio, leídas en el concilio. ${ }^{109}$

\section{CONCLUSIÓN}

La controversia priscilianista se desarrolló en distintos planos: doctrinal, eclesiástico, judicial, personal y político. La usurpación de Máximo modificó sustancialmente su desenlace. No obstante, sus actuaciones no estuvieron inspiradas por su nicenismo, sino por el pragmatismo de un hombre de poder obligado a responder a las exigencias del momento. Su inclinación religiosa personal fue factor secundario en su intervención en el conflicto. Los conflictos religiosos no eran la parte fundamental en la agenda política de Máximo, pese a la atención que le dedican las fuentes cristianas. ${ }^{110} \mathrm{Sin}$ embargo, la disputa priscilianista y la crisis de las basílicas de Milán le proporcionaron un nuevo ámbito de actuación y la ocasión para debilitar la posición de Valentiniano II en Milan. Su compromiso con la ortodoxia nicena en el conflicto priscilianista contrastaba con la derrota del homeísmo de Valentiniano II ante Ambrosio. En las dos cartas conservadas en la Avellana, redactadas prácticamente a la vez en 386, Máximo exponía ante Valentiniano y Siricio los argumentos que había escuchado a Martín de Tours y a Ambrosio:

104 Ambr. ep. 41 (Maur. 86); 46 (Maur. 85); extra coll. 15 (Maur. 41a); Sir. ep. 7 (Maur.41a).

105 Sulp. Sev. Chron. 2, 51, 4-5.

106 En el S. V, Inocencio, Jerónimo y León Magno considerarán justamente condenado a Prisciliano: Innoc. I, ep. 3; Hier. ep. 133, 3; Leo I, ep. 15, 7.

107 Lib. Pont. I, 216. Sobre la desconfianza hacia los arrepentidos. Vid. Perrin 2010; Escribano Paño 2015.

108 Sir. ep. 7 (Maur.41a). 3. Vid. Hunter 2003.

109 Conc. Taur. c. 6. 398. Vid. Kulikowski 1996, que retrasa la fecha del concilio. Cf. Matishen 2013.

110 Vid. Harries 1978, 38. 
el emperador no debía interferir de manera directa en las disputas heréticas; debía delegar en los obispos, a quienes correspondía resolver los conflictos internos de las iglesias. Ambas epístolas defendían el sometimiento del emperador a las decisiones conciliares y la no injerencia imperial directa del emperador en los conflictos entre sacerdotes. El análisis de la iniciativa de Máximo en la disputa priscilianista demuestra que estaba dispuesto a imponer la unidad y acabar con la discordia, en todo caso perjudicial para su causa, pero en colaboración con los obispos y aplicando las leyes y los procedimientos públicos, según demandaban sus particulares circunstancias políticas.

\section{BibLIOGRAFÍA}

Babut, Ernest Ch. 1909. Priscillien et le Priscillianisme. Paris: Librairie Honoré Champion.

Babut, Ernest Ch. 1912. S. Martin de Tours. Paris: Librairie Honoré Champion.

Baldus, Hans Roland. 1984. "Theodosius der Grosse und die Revolte des Magnus Maximus-der Zeugnis der Münzen». Chiron 14: 175-1 92.

Barnes, Timothy David. 2000. «Ambrosio and the Basilicas of Milan in 385 and 386. The Primary Documents and their Implications». ZAC 4: 282-299.

Barnes, Timothy David. 2002. «Valentinian, Auxentius and Ambrosio». Historia 51: 227-237.

Beskow, Per. 1988. "The Theodosian Laws against Manichaeism». En Manichaean Studies, 1-11. Lund: Lund Plus Ultra.

Binsfeld, Andrea. 2003. "Das Bistum Trier von den Anfängen bis zum Ende der Römerzeit (3. - 5. Jahrhundert)». En Im Umbruch der Kulturen: Spätantike und Frühmittelalter, ed. Heinen Heinen, Anton Hans Hubert y Weber Winfried, 59-63. Trier: Geschichte des Bistums Trier.

Birley, Anthony. 1983. "Magnus Maximus and the Persecution of Heresy". Bulletin of the John Rylands University Library of Manchester 66: $13-43$.

Blair-Dixon, Kate. 2007. "Memory and Authority in Sixth-Century Rome: the Liber Pontificalis and the Collectio Avellana». En Religion, Dynasty, and Patronage in Early Christian Rome (300-900) ed. Kate Cooper y Julia Hillner, 22-59. Cambridge: Cambridge University Press.

Breyfogle Todd. 1995. "Magic, Women, and Heresy in the Late Empire: The Case of the Priscillianists». En Ancient Magic and Ritual Power ed. Marvin Meyer y Paul Mirecki, 435-454. Leiden-New York-Köln: Brill.

Burrus, Virginia. 1995. The Making of a Heretic. Gender, Authority, and the Priscillianist Controversy. Berkeley: University of California Press.

Callam, Daniel. 1980. "Clerical Continence in the Fourth Century: Three Papal Decretals». Theological Studies 41: 3-50.

Cameron, Alan. 2007. «The Imperial pontifex». Harvard Studies in Classical Philology 103: 341-387.

Casey, John. 1979. "Magnus Maximus in Britain». En The End of Roman Britain, ed. John Casey, 66-79. British Series, 71. Oxford: B.A.R.

Chadwick, Henry. 1976. Priscillian of Avila. Oxford: Clarendon Press.

Croke Brian. 2010. "Reinventing Constantinople: Theodosius I's Imprint on the Imperial City". En From the Tetrarchs to the Theodosians: Later Roman History and Culture, 284 - 450 CE, ed. Scott McGill, Cristiana Sogno y Edward Watts, 241-264. Cambridge - New York: Cambridge University Press.

Dörner, Norbert. 2001. «Ambrosius in Trier Zu den Hintergründen der zweiten Gesandtschaft bei Maximus (Ambrosius, epist. 30 [24])». Historia 50: 217-244.

Duchesne, Louis. 1915. Fastes Episcopaux de l'ancienne Gaule III, 3044. Paris: Fontemoing
Duval, Yves Marie. 2002. "Les ambassades de Saint Ambroise auprès de l'usurpateur Maxime en 383 et 384». En Humana sapit: études d'Antiquité tardive offertes à Lellia Cracco Ruggini, ed. Jean-Michel Carrié y Rita Lizzi, 239-251. Turnhout: Brepols.

Ensslin, Wilhelm. 1930. «Maximus» 33. RE 14: 2546-2555.

Errington, Robert Malcolm. 1997. «Church and State in the First Years of Theodosius I». Chiron 27: 21-72.

Errington, Robert Malcolm. 2006. Roman Imperial Policy from Julian to Theodosius. Chapel Hill: University of North Carolina Press.

Escribano Paño, María Victoria. 1988. Iglesia y Estado en el certamen priscilianista, Causa ecclesiae y iudicium publicum. Zaragoza: Universidad de Zaragoza.

Escribano Paño, María Victoria. 1994. «Haeretici iure damnati: el proceso de Tréveris contra los priscilianistas (385)». En Studia Ephemeridis Augustinianum 46, XXII Incontro di studiosi dell'antichità cristiana, Cristianesimo e specificità regionali nel Meditarraneo latino, secoli IV-VI, 393-416. Roma: Institutum Patristicum Augustinianum.

Escribano Paño, María Victoria. 2002. «Magia, maniqueísmo y cristianismo. El I Concilio de Caesaraugusta (ca. 379)». En Studia Ephemeridis Augustinianum 78, XXX Incontro di estudiosi dell'Antichità cristiana: I concili della cristianità occidentale. Secoli III-V, 89-116. Roma: Institutum Patristicum Augustinianum.

Escribano Paño, María Victoria. 2005. "Heresy and Orthodoxy in Fourth Century Hispania». En Hispania in Late Antiquity. Current Perspectives, ed. Kim Bowes y Michael Kulikowski, 121-149. Leiden - Boston: Brill.

Escribano Paño, María Victoria. 2011. «From Norm to Identity: Christians and Manichaeans in Codex Theodosianus XVI: Separated by the Law». En Figures de l'empire, fragments de mémoire: pouvoirs et identités dans le monde romain imperial (II s. av.n.e.-VI s. de n.e.), dir. Stéphane Benoist, Anne Daguet-Gagey y Christine Hoëtvan Cauwenberghe, 503-529. Villeneuve d'Ascq: Presses Universitaires du Septentrion.

Escribano Paño, María Victoria. 2012. «La limitación de los derechos testamentarios a los maniqueos en las leyes del Codex Theodosianus 16,5,7 (381) y 16,5,9 (382)». En Accademia Romanistica Costantiniana, XVIII Convegno Internazionale, "Persona» e persone nella società en el diritto della tarda antichità, 113-142. Perugia: Aracne.

Escribano Paño, María Victoria. 2015. «Simulatio, abjuración y delación de maniqueos en África: el testimonio de Agustín». Antiquité Tardive 23: 383-394. https://doi.org/10.1484/J.AT.5.109390

Escribano Paño, María Victoria. 2017. «Legenda sunt gesta ad sanandas animas: leyes, juicios y actas para la correctio de los donatistas en Agustín de Hipona». Antiquité Tardive 25: 95-106. https://doi. org/10.1484/J.AT.5.114863

Escribano Paño, María Victoria. 2019. «Maximus’ Letters In The Collectio Avellana: A Comparative Study». En The Collectio Avellana and Its Revivals, ed. Rita Lizzi y Giulia Marconi, 50-85. Cambridge: Cambridge Scholars Publishing.

Ferreiro, Alberto. 2015. «Pope Siricio and Himerius of Tarragona (385): Provincial Papal Intervention in the Fourth Century». En The Bishop of Rome in late Antiquity, ed. Geoffrey D. Dunn, 73-85. Farnham: Ashgate.

Fontaine, Jacques. 1967-1969. Vie de Saint Martin, I-III. Paris: Le Editions du Cerf.

Gaudemet, Jean. 1977. Conciles gaulois du IVe siècle. Paris: Les Edfitions du Cerf.

Girardet, Klaus. 1974. «Trier 385. Der Prozess gegen die Priscillianer». Chiron 4: 577-608.

Harries, Jill. 1978. "Church and State in the Notitia Galliarum» JRS 68: 26-43.

Hornung, Christian. 2015. "Siricio and the Rise of the Papacy». En The Bishop of Rome in late Antiquity, ed. Geoffrey D. Dunn, 57-65. Farnham: Ashgate.

Humphries, Mark. 2008. «From Usurper to Emperor: The Politics of Legitimation in the Age of Constantine». Journal of Late Antiquity 1: $82-100$. 
Hunter, David G. 2003. «Rereading the Jovinianist Controversy: Ascetism and Clerical Authority in Late Ancient Christianity». Journal of Medieval and Early Modern Studies 33: 453-470.

Kaden, Erich-Hans. 1953. «Die Edikte gegen die Manichäer von Diokletian bis Justinian». En Festschrift Hans Lewald, 55-68. Basel: Helbing \& Lichtenhahn.

Kahlos, Maijastina. 2016. "Artis heu magicis: The Label of Magic in Fourth Century Conflicts and Disputes». En Pagans and Christians in Late Antique Rome, ed. Michele Salzmann, Marianne Sághy y Rita Lizzi Testa, 162-177. Cambridge - New York: Cambridge University Press.

Kelly, Christopher. 2014. "Pliny and Pacatus, Past and Present in Imperial Panegyric». En Contested Monarchy. Integrating the Roman Empire in the Fourth Century AD, ed. Johannes Wienand, 215-238. Oxford: Oxford University Press.

Kulikowski, Michael. 1996. «Two Councils of Turin». Journal of Theological Studies 47: 159-168.

Liebeschuetz, John Hugo Wolfgang Gideon. 2005. Ambrosio of MiIan, Political Letters and Speeches. Liverpool: Liverpool University Press.

Lizzi Testa, Rita. 2008. «Martino vescovo santo: un nuovo modelo di santità nell' Occidente tardoantico». Cristianesimo nella Storia 29: 317-344.

Lizzi Testa, Rita. 2009. "La certatio fra Ambrogio e Mercurino Aussenzio, ovvero a proposito di una deposizione mancata». Studia Ambrosiana, Saggi e ricerche su Ambrogio e l'età tardoantica 3: 39-68.

Lizzi Testa, Rita. 2014. "La Collectio Avellana e le collezioni canoniche romane e italiche del V-VI secolo: un progetto di ricerca». Cristianesimo nella Storia 35: 77-102.

Lunn-Rockliffe, Sophie. 2010. «Commemorating the Usurper Magnus Maximus: Ekphrasis, Poetry, and History in Pacatus' Panegyric of Theodosius». Journal of Late Antiquity 3: 316-336.

Matishen, Ralph. 2013. "The Council of Turin (398/399) and the Reorganization of Gaul ca. 395/406». Journal of Late Antiquity 6 (2): 264-307.

McEvoy, Meaghan A. 2013. Child Emperor Rule in the Late Roman West, $A D$ 367-455. Cambridge: Cambridge University Press.

McLynn, Neil. 1994. Ambrosio of Milan: Church and Court in a Christian Capital. Berkeley and Los Angeles: University of California Press.

McLynn, Neil. 2004. "The Transformation of Imperial Churchgoing in the Fourth Century». En Approaching Late Antiquity. The Transformation from Early to Late Antiquity, ed. Simon Swain y Mark Edwards, 234-270. Oxford: Oxford University Press.

McLynn, Neil. En prensa. «Tyrants, Arians, and Manichees: Magnus Maximus in the Collectio Avellana». En Emperors, Bishops, Senators: The Evidence of the Collectio Avellana, ed. Alexander Evers. Leuven: Peeters.

Neri, Valerio. 2014. «La repressione penale della magia: principi e prassi giudiziaria, le testimonianze Antiochene». En Politica, religione e legislazione nell'impero romano (IV e V secolo d. C.), ed. María Victoria Escribano Paño y Rita Lizzi Testa, 199-214. Bari: Edipuglia.

Omissi, Adrastos. 2018. Emperors and Usurpers in the Later Roman Empire, Civil War, Panegyric, and the Construction of Legitimacy. Oxford: Oxford University Press.

Palanque, Jean-Rémy. 1929. "Sur l'usurpation de Maxime». REA 31: 33-36.

Palanque, Jean-Rémy. 1965. «L'empereur Maxime». En Les empereurs romains d'Espagne, ed. André Piganiol y Henri Terrasse, 255-263. Paris: Centre National de la Recherche Scientifique.

Perrin, Michel-Yves. 2010. «Crevit hypocrisis. Limites d’adhésion au christianisme dans l'Antiquité tardive: entre histoire et historiographie». En Le problème de la christianisation du monde Antique, en ed. Hervé Inglebert, Sylvain Destephen y Bruno Dumézil, 47-62. Paris: Édition de Picard.

Prinz, Friedrich. 1982. Frühes Monchtum im Frankenreich. Kultur und Gesellschaft in Gallien, den Rheinlanden und Bayern am Beispiel der monastischen Entwicklung (4. bis 8. Jahrhundert). München: De Gruyter.

Proulx, Michael. 2010. «Patres orphanorum: Ambrosius of Milan and the Construction of the Role of the Bishop». En The Rhetoric of Power in Late Antiquity: Religion and Politics in Byzantium, Europe and the Early Islamic World, ed. Robert Frakes, Elizabeth DePalma Digeser, and Justin Stephens, 75-97. London - New York: Tauris Academic Studies.

Raschle, Christian. 2005. "Ambrosius'Predigt gegen Magnus Maximus: eine historische Interpretation der explanatio in psalmum 61 (62)». Historia 54: 225-243.

Rees, Roger. 2004. Diocletian and the Tetrarchy. Edinburgh: Edinburgh University Press.

Rives, James. 2003. "Magic in Roman Law: The Reconstruction of a Crime». Classical Antiquity 22: 313-339.

Roberts, Michael. 1995. "Martin meets Maximus: the Meaning of a Late Roman Banquet». Revue des Études Augustiniennes 41: 91111.

Rodríguez, Félix. 1981. Concilio I de Zaragoza, Texto crítico. En I concilio Caesaraugustano. MDC aniversario. Zaragoza: IFC.

Rogers, Walter Eugene. 1997. Magnus Maximus: Portrait of a Usurper. Carolina: University of South Carolina.

Rousseau, Philip. 1996. "Ambrosio and the Christian Empire: Some Misgivings». En Religion in the Ancient World: New Themes and Approaches, ed. Matthew Dillon, 477-489. Amsterdam: Adolf M. Hakkert.

Sardella, Teresa. 1995. «Papa Siricio e i movimenti ereticali nella Spagna di Teodosio I». En Actas del Congreso internacional La España de Teodosio, ed. Ramón Teja y Cesáreo Pérez González, 247-254. Salamanca: Junta de Castilla y León - Universidad SEK.

Stockmeier, Peter. 1967. «Das Schwert im Dienste der Kirche. Zur Hinrichtung Priszillians in Trier». En Festschrift für Alois Thomas. Archäologische, kirchen- und kunsthistorische Beiträge, 415-428. Trier: Selbstvlg. d. Bistumsarchivs.

Taubenschlag, Rafael. 1928. "Maleficium». RE 14: 870-875.

Teja, Ramón. 2012. «Quid episcopis cum palatio? Cuando los obispos se sentaron a la mesa con Constantino». En Costantino prima e dopo Costantino, ed. Giorgino Bonamente, Noel Lenski y Rita Lizzi Testa, 209-224. Bari: Edipuglia.

Vera, Domenico. 1975. «I rapporti fra Magno Massimo, Teodosio e Valentiniano II nel 383-384». Athenaeum 53: 267-301.

Vilella, Josep. 1997. «Un obispo-pastor de época teodosiana: Prisciliano». En Studia Ephemeridis Augustinianum, XXV Incontro di studiosi dell'antichità cristiana, Vescovi e pastori in epoca teodosiana, 503-530. Roma: Institutum Patristicum Augustinianum.

Vilella, Josep. 2004. «La epistola 1 de Siricio: Estudio prosopográfico de Himerio de Tarragona». Augustinianum 44: 337-369.

Vollmann, Benedikt. 1974. «Priscillianus». RE 14: cols. 485-559.

Wiebe, Franz Josef. 1995. «Kaiser Valens und die heidnische Opposition». Antiquitas 44: 86-168.

Williams, Daniel H. 1995. Ambrosio of Milan and the End of the ArianNicene Conflicts. Oxford: Clarendon Press.

Williams, Michael Stuart. 2017. The Politics of Heresy in Ambrosio of Milan, Comunity and Consensus in Late Antique Christianity. Cambridge: Cambridge University Press.

Ziegler, Joachim. 1970. Zur religiösen Haltung der gegenkaiser im 4. Jh. N. Chr. Kalmünz: Michael Lassleben. 